Article

\title{
Facile Preparation of Highly Stretchable and Recovery Peptide-Polyurethane/Ureas
}

\author{
Lin $\mathrm{Gu}^{1,2,+(\mathbb{D}) \text {, Yuanzhang Jiang }}{ }^{2,+(\mathbb{D})}$ and Jinlian $\mathrm{Hu}^{2, *(1)}$ \\ 1 Key Laboratory of Marine Materials and Related Technologies, Key Laboratory of Marine Materials and \\ Protective Technologies of Zhejiang Province, Ningbo Institute of Materials Technology and Engineering, \\ Chinese Academy of Sciences, Ningbo 315201, China; lin.gu@polyu.edu.hk \\ 2 Institute of Textiles \& Clothing, The Hong Kong Polytechnic University, Hong Kong 999077, China; \\ yuan-zhang.jiang@connect.polyu.hk \\ * Correspondence: jin-lian.hu@polyu.edu.hk; Tel.: +852-2766-643 \\ + These authors contributed equally to this work.
}

Received: 7 May 2018; Accepted: 5 June 2018; Published: 8 June 2018

\begin{abstract}
In this work, a new class of highly stretchable peptide-polyurethane/ureas (PUUs) were synthesized containing short $\beta$-sheet forming peptide blocks of poly ( $\gamma$-benzyl-L-glutamate)- $b$ poly(propylene glycol)- $b$-poly ( $\gamma$-benzyl-L-glutamate) (PBLG- $b$-PPG- $b$-PBLG), isophorone diisocyanate as the hard segment, and polytetramethylene ether glycol as the soft phase. PBLG- $b$-PPG- $b$-PBLG with short peptide segment length ( $<10$ residues) was synthesized by amine-initiated ring opening polymerization of $\gamma$-benzyl-L-glutamate- $N$-carboxyanhydrides (BLG-NCA), which shows mixed $\alpha$-helix and $\beta$-sheet conformation, where the percent of $\beta$-sheet structure was above $48 \%$. Morphological studies indicate that the obtained PUUs show $\beta$-sheet crystal and nanofibrous structure. Mechanical tests reveal the PUUs display medium tensile strength $(0.25-4.6 \mathrm{MPa})$, high stretchability $(>1600 \%)$, human-tissue-compatible Young's modulus (226-513 KPa). Furthermore, the shape recovery ratio could reach above $85 \%$ during successive cycles at high strain (500\%). In this study, we report a facile synthetic method to obtain highly stretchable and recovery peptide-polyurethane/urea materials, which will have various potential applications such as wearable and implantable electronics, and biomedical devices.
\end{abstract}

Keywords: polyurethane/urea; poly( $\gamma$-benzyl-L-glutamate); $\beta$-sheet conformation; shape recovery

\section{Introduction}

Nature utilizes an intriguing strategy to yield biomaterials with high performance characteristics, such as stiffness, toughness, and extensibility by exploring hierarchical architecture [1,2]. An examination of natural structural proteins, such as silks, collagens, and elastins, reveals that hierarchical long-range ordered structures of peptides play a critical role in achieving superior mechanical properties $[3,4]$. For example, spider silks exhibit perfect balance between strength and toughness due to their $\beta$-sheet, $\alpha$-helical, and random coil structures [5]. Among them, $\beta$-sheet nanocrystals have been identified as a key component responsible for its excellent mechanical properties [6,7]. By contrast, elastins achieve high stretchability and resilience by covalently crosslinking of short peptide chains [8]. Given their architectural feature and unique properties, the use of structural proteins as building blocks for material design will have tremendous promises in various potential applications such as cell scaffolding, tissue engineering, and smart materials [9]. However, harvesting these natural proteins in large scale is so far difficult. 
In recent decades, genetic engineering has been used widely to produce various protein materials with precisely controlled sequences and tailored functions, but this method is costly and inappropriate for mass production [9,10]. Nowadays, chemical synthesis of peptide-based biopolymers to mimic natural proteins has drawn more attention since this process is facile, cost effective, and energy efficient in large scale $[9,10]$. Recently, Tsuchiya et al. developed multiblock copolypeptides polyAla-b-poly(Gly-r-Leu) via a two-step chemical synthesis method, which could mimic the secondary structures of dragline spider silks [10]. The Sogah group prepared tetrapeptide (Gly-Ala-Gly-Ala or [Ala $]_{4}$ )-containing copolymers, whose mechanical properties were similar to those of regenerated spider silks [11-13]. Martino et al. reported the chemical synthesis of cross-linked poly(Orn-Gly-Gly-Orn-Gly), which could mimic almost entirely the physical-chemical properties of elastins, and display similar elastic properties [14].

On the other hand, nature-inspired peptidic segments have been incorporated into polymers to tailor the material properties due to their ability to precisely control second structures [15]. Clarke et al. developed physically cross-linked hybrid hydrogels via grafting $\beta$-sheet peptides to a poly $(\gamma$-glutamic acid) backbone [16]. These $\beta$-sheet peptides provide strong non-covalent cross-links, allowing the hydrogels self-heal after being strained to failure. Hu et al. synthesized shape memory biopolymers containing $\beta$-sheet polyalanine segments [17]. The $\beta$-sheet crystals act as netpoints, allowing the biopolymers to exhibit excellent shape recovery ability and high shape fixity. Tanaka et al. prepared well-defined poly ( $\gamma$-benzyl-L-asparate)- $b$-poly(ethylene oxide)- $b$-poly $(\gamma$-benzyl-L-asparate) (PBLA- $b$-PEO- $b$-PBLA) triblocks, which exhibited excellent strength and flexibility [18]. The extensions could reach $500 \%$ from $200 \%$ after thermal treatment, which was attributed to a second structural transformation in PBLA, from $\alpha$-helix to $\beta$-sheet. Korley et al. utilized peptidic order (specifically $\beta$-sheets) to design hierarchical polyurethane/ureas [15]. The existence of $\beta$-sheets made the tensile modulus three-fold increase, but the extension was dramatically reduced. Furthermore, Korley et al. also investigated the effects of second structure and hydrogen-bonding arrangement on the mechanical properties of peptide-polyurea hybrids $[19,20]$. It was found that increased toughness was attributed to $\beta$-sheets ordering, and modulus was increased with increased peptide weight fraction.

In this work, a new class of highly stretchable and recovery peptide-polyurethane/ureas (PUUs) were synthesized containing short $\beta$-sheet forming peptide blocks. The obtained PUUs display medium tensile strength $(0.25-4.6 \mathrm{MPa})$, high stretchability $(>1600 \%)$, human-tissue-compatible Young's modulus $(226-513 \mathrm{KPa})$, and high shape recovery ratio $(\sim 80 \%)$ during successive cycles at high strain $(500 \%)$, similar to those of elastins. We believe this work will provide new insight for developing highly stretchable polypeptide materials, which would have various potential applications such as wearable and implantable electronics, and biomedical devices.

\section{Experimental Section}

\subsection{Materials}

$\gamma$-Benzyl-L-glutamate (BLG) and triphosgene were obtained from J \& K Scientific Ltd. (Beijing, China). Poly(propylene glycol) bis(2-aminopropyl ether) (PPG-diamine 2000, average $M_{n} \sim 2000$ ) was purchased from Aldrich (Beijing, China) and dried at $80{ }^{\circ} \mathrm{C}$ in vacuum for $6 \mathrm{~h}$ prior to use. Polytetramethylene ether glycol (PTMEG 2000, average $M_{\mathrm{n}} \sim 2000$ ) was supplied by Shanghai Macklin Biochemical Co., Ltd. (Shanghai, China) and dried at $80{ }^{\circ} \mathrm{C}$ in vacuum for $2 \mathrm{~h}$ prior to use. Isophorone diisocyanate (IPDI) was purchased from Acros Organics (Beijing, China) and used as received. Tetrahydrofuran (THF) and $\mathrm{N}$-dimethylformamide (DMF) were dried over $\mathrm{CaH}_{2}$ and distilled before use. 
2.2. Synthesis of Poly( $\gamma$-benzyl-L-glutamate)-b-poly(propylene glycol)-b-poly( $\gamma$-benzyl-L-glutamate) (PBLG-b-PPG-b-PBLG) Triblock

$\gamma$-Benzyl-L-glutamate- $N$-carboxyanhydride (BLG-NCA) was prepared from BLG and triphosgene in THF according to the literatures $[21,22]$. Poly ( $\gamma$-benzyl-L-glutamate)- $b$-poly(propylene glycol)- $b$-poly $(\gamma$ benzyl-L-glutamate) (PBLG- $b$-PPG- $b$-PBLG) triblock was synthesized by amine-initiated BLG-NCA polymerization, as shown in Scheme 1. In a $\mathrm{N}_{2}$ atmosphere, $34.6 \mathrm{~g}$ BLG NCA (131.5 mmol), $26.3 \mathrm{~g}$ PPG-diamine 2000 (13.15 mmol), and $350 \mathrm{~mL}$ DMF were introduced into a flame-dried $1 \mathrm{~L}$ flask. The reaction was performed at room temperature for 3 days. The reaction mixture was precipitated into deionized water and filtered. The obtained solid was fractionated by treatment with isopropanol (IPA). The IPA-insoluble fraction was filtered and dried at $50{ }^{\circ} \mathrm{C}$ in vacuum to yield $\mathbf{P 7}(19 \mathrm{~g})$. The filtrate was dried at $50{ }^{\circ} \mathrm{C}$ in vacuum to yield $\mathbf{P 3}(27 \mathrm{~g})$.
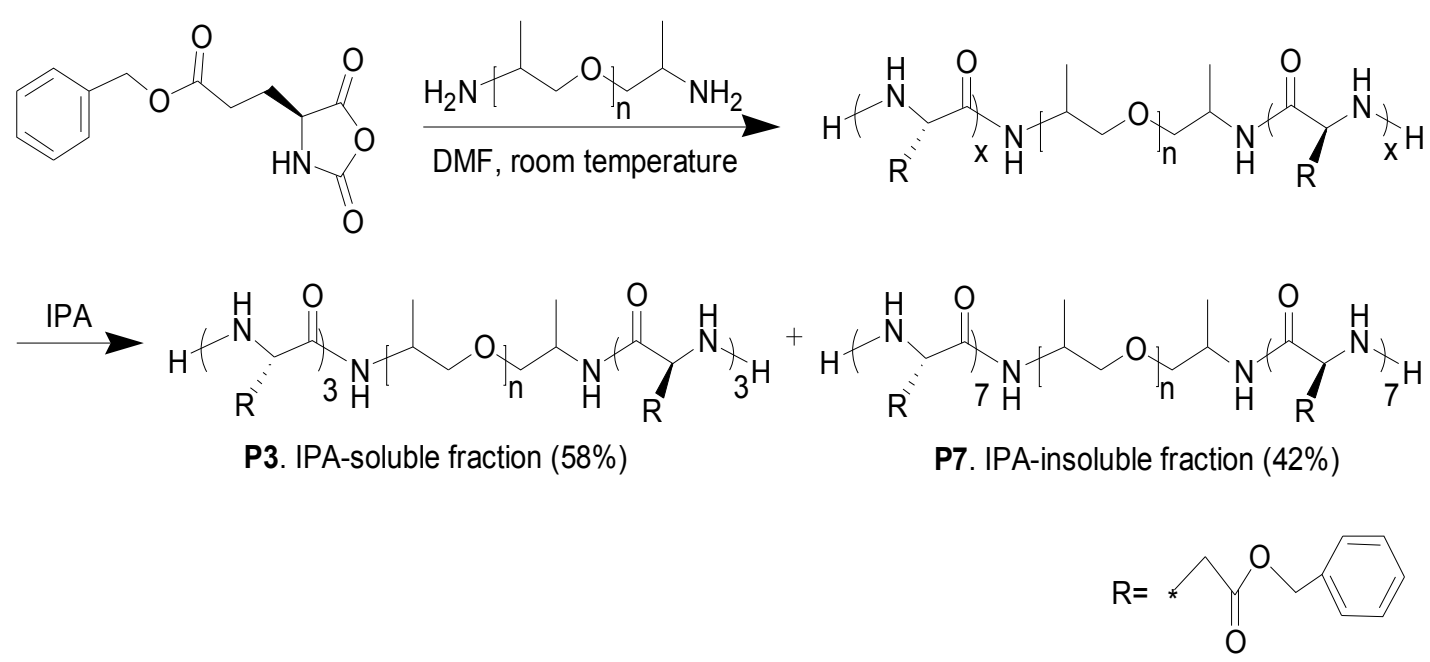

Scheme 1. Synthesis of poly( $\gamma$-benzyl-L-glutamate)-b-poly(propylene glycol)- $b$-poly $(\gamma$-benzyl-L-glutamate $)$ (PBLG-b-PPG-b-PBLG) triblock.

\subsection{Preparation of Peptide-Polyurethane/Ureas and Films}

The peptide-polyurethane/ureas were prepared via a two-step polymerization process following Scheme 2 according to the literatures [23-25], where the molar ratio of PTMEG 2000, IPDI, and peptidic triblock (P3 or P7) was 3:4:1. First, prepolymerization of PTMEG 2000 with IPDI catalyzed by dibutyltin dilaurate was performed at $80{ }^{\circ} \mathrm{C}$ for $3 \mathrm{~h}$. Second, the DMF solution of peptidic triblock was added and the reaction was carried out for another $3 \mathrm{~h}$.
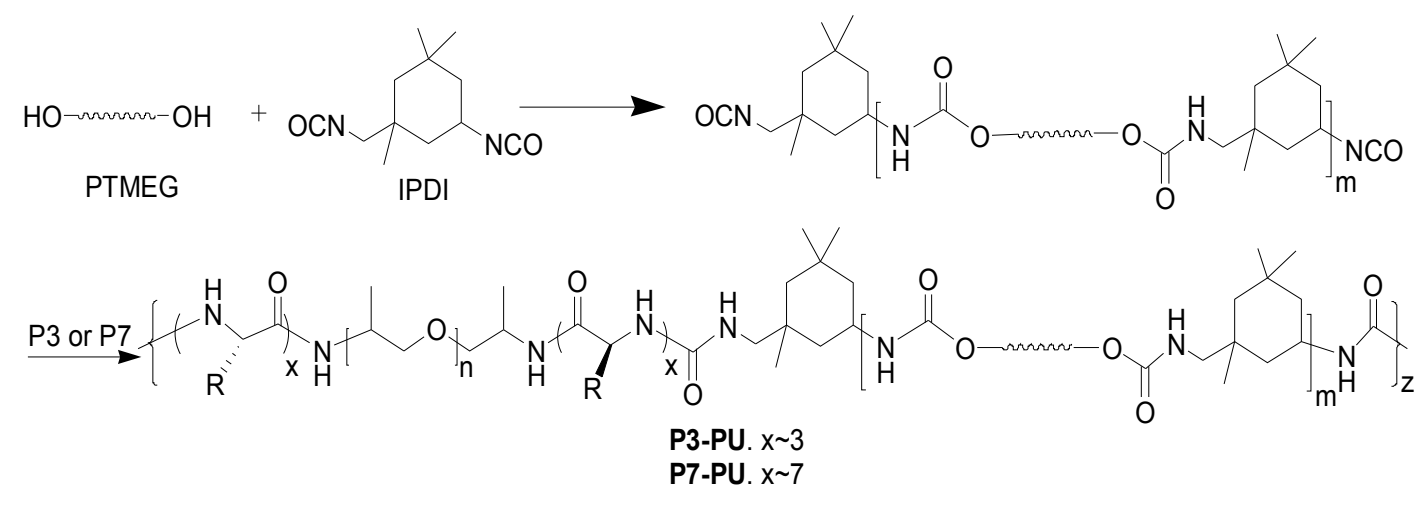

Scheme 2. Synthesis of the obtained peptide-polyurethane/ureas (P3-PU and P7-PU). 
The obtained peptide-polyurethane/urea (P3-PU or P7-PU) was dissolved in DMF to form a $10 \mathrm{wt} \%$ solution. The solution was poured into a Teflon mold and dried at $80^{\circ} \mathrm{C}$ for $24 \mathrm{~h}$, and then further dried in vacuo at $50{ }^{\circ} \mathrm{C}$ for $10 \mathrm{~h}$.

\subsection{Characterization}

${ }^{1} \mathrm{H}$ and ${ }^{13} \mathrm{C}$ NMR spectra of the obtained peptidic triblocks were obtained in $\mathrm{CDCl}_{3} / \mathrm{CF}_{3} \mathrm{COOD}$ $(3 / 1, v / v)$ using an Avance III $400 \mathrm{MHz}$ spectrometer (Bruker, Billerica, MA, USA). Fourier transform infrared (FTIR) spectra were recorded on a Spectrum 100 FTIR spectrometer (PerkinElmer, Waltham, MA, USA). Differential scanning calorimetry (DSC) analysis was conducted on a DSC 8000 instrument (PerkinElmer, Waltham, MA, USA) under a $\mathrm{N}_{2}$ flow from $-60{ }^{\circ} \mathrm{C}$ to $200{ }^{\circ} \mathrm{C}$ at a rate of $20{ }^{\circ} \mathrm{C} \mathrm{min}-1$. Thermogravimetric analysis (TGA) was performed on a thermal analyzer (METTLER TOLEDO, Greifensee, Switzerland) under a $\mathrm{N}_{2}$ flow from $50{ }^{\circ} \mathrm{C}$ to $600^{\circ} \mathrm{C}$ at a heating rate of $10{ }^{\circ} \mathrm{C} \mathrm{min}^{-1}$. Wide angle X-ray diffraction (WAXD) data were collected on an X-ray diffractometer (Rigaku SmartLab, Tokyo, Japan) from diffraction angle $2 \theta=5^{\circ}$ to $65^{\circ}$ at a speed of $10^{\circ} / \mathrm{min}$ using $\mathrm{Cu} \mathrm{K} \alpha$ radiation (1.54 $\AA$ ). Atomic force microscopy (AFM) was performed on a scanning probe microscope (Bruker NanoScope 8, Bruker, Billerica, MA, USA).

Tensile test was carried out on an Instron 5566 instrument with a speed of $20 \mathrm{~mm} / \mathrm{min}$ at room temperature $\left(22^{\circ} \mathrm{C}\right)$. Cyclic tensile test was also conducted on the same machine. First, the sample was stretched to a strain $\varepsilon_{\mathrm{m}}$ at room temperature with a speed of $100 \mathrm{~mm} / \mathrm{min}$. Then, the clamp began to return until the force on the sample was 0 , and the residual elongation was $\varepsilon_{\mathrm{p}}$. After the above two steps, one cycle is complete. The shape recovery rate $\left(R_{\mathrm{r}}\right)$ was calculated according to the following formula ( $N$ is the cyclic number):

$$
R_{\mathrm{r}}(N)=\frac{\varepsilon_{\mathrm{m}}-\varepsilon_{\mathrm{p}}(N)}{\varepsilon_{\mathrm{m}}-\varepsilon_{\mathrm{p}}(N-1)} \times 100 \%
$$

\section{Results and Discussion}

\subsection{Synthesis and Characterization of Peptidic Triblocks}

As shown in Scheme 1, PBLG-b-PPG-b-PBLG was synthesized by amine-initiated ring opening polymerization of BLG-NCA, where the molar ratio of monomer and initiator is 10 . The obtained peptidic triblock was fractionated into IPA-soluble (P3) and IPA-insoluble (P7) components. The structure of these two components was characterized by NMR and FTIR. Figure 1A displays the ${ }^{1} \mathrm{H}$ NMR spectra of $\mathbf{P} 3$ and P7. The signals at $7.3 \mathrm{ppm}$ and $5.2 \mathrm{ppm}$ ascribed to the protons on phenyl and $\mathrm{CH}_{2}$ in benzyl group, respectively, and the characteristic peak at $4.7 \mathrm{ppm}$ is assigned to $\mathrm{CH}$ groups in amide linkage. The signals at $1.3,3.7$, and $3.9 \mathrm{ppm}$ are assigned to $\mathrm{CH}_{3}, \mathrm{CH}_{2}$, and $\mathrm{CH}$ groups in the PPG units. The molecular weights of P3 and P7 were calculated to be $\sim 3314$ and $~ 5066$, respectively, according to the integral area ratio of the $\mathrm{CH}_{2}$ peak at $5.2 \mathrm{ppm}$ to $\mathrm{CH}_{2}$ peak at $3.7 \mathrm{ppm}$. These correspond to $\sim 6$ and $\sim 14$ BLG residues, respectively, which are equivalent to an average degree of polymerization (DP) of 3 and 7 for each PBLG block. Figure 1B shows the ${ }^{13} \mathrm{C}$ NMR spectra of the samples. The existence of the characteristic peaks of PPG-diamine at 71-76 ppm confirmed the formation of peptidic triblocks. 
(A)
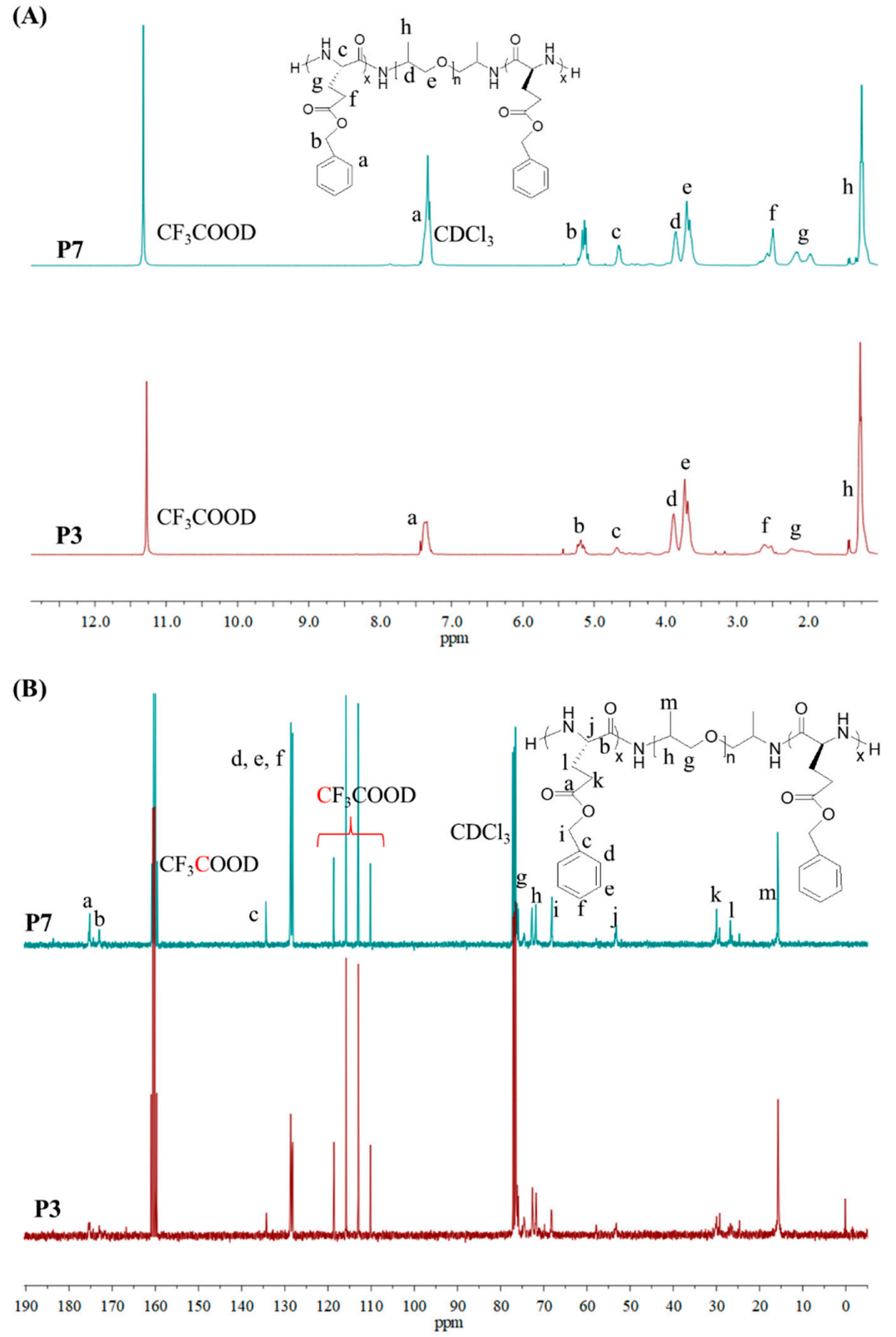

Figure 1. ${ }^{1} \mathrm{H}(\mathbf{A})$ and ${ }^{13} \mathrm{C}$ (B) NMR spectra of PBLG-b-PPG-b-PBLG (P3 and P7).

Figure 2 shows the FTIR spectra of $\mathbf{P 3}$ and P7. The amide I ( $\mathrm{C}=\mathrm{O}$ stretch) region that is present at $1600-1700 \mathrm{~cm}^{-1}$ could be employed to determine the structure (e.g., $\beta$-sheet, $\alpha$-helix) of polypeptides $[21,26]$. The strong band of $\beta$-sheet occurs at $1636-1640 \mathrm{~cm}^{-1}$ (parallel) or 1622-1632 $\mathrm{cm}^{-1}$ (antiparallel). The amide I peak is located at higher wavenumbers for a left-handed $\alpha$-helix $\left(\sim 1668 \mathrm{~cm}^{-1}\right)$ compared to a right-handed $\alpha$-helix $\left(\sim 1655 \mathrm{~cm}^{-1}\right)$. Besides, it has been reported that PBLG is more likely to form a $\alpha$-helix confirmation when DP $>10$ and a $\beta$-sheet when DP $<10$ [26]. As shown in Figure 2, it can be clearly seen that the obtained P3 and P7 not only forms antiparallel $\beta$-sheet structure, but also has right-handed $\alpha$-helix as previously reported for PBLG- $b$-PDMS- $b$-PBLG [27]. The percent of $\beta$-sheet conformation in P3 and P7 were calculated to be $\sim 83.0 \%$ and $48.4 \%$ by the deconvolution of the amide I region (1600-1670 $\left.\mathrm{cm}^{-1}\right)$, respectively. The shorter the peptide segment PBLG is, the greater is the tendency to form $\beta$-sheet aggregated. 


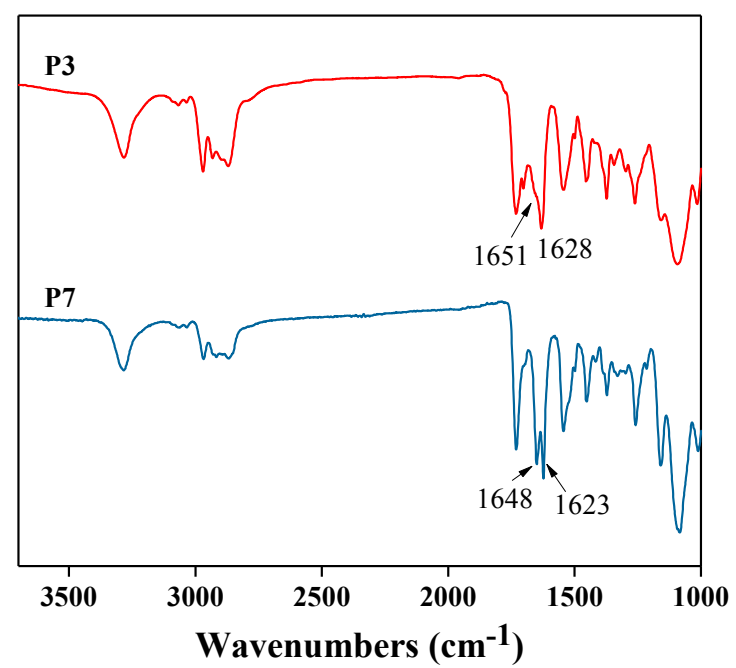

Figure 2. Fourier transform infrared (FTIR) spectra of P3 and P7.

Figure 3 shows the DSC curves of obtained $\mathbf{P} 3$ and $\mathbf{P 7}$, and their $T_{\mathrm{g}} \mathrm{s}$ and $T_{\mathrm{m}} \mathrm{s}$ values are listed in Table 1. The glass transition temperatures $\left(T_{\mathrm{g}} \mathrm{s}\right)$ around $30{ }^{\circ} \mathrm{C}$ were detected, corresponding to the PBLG units [28] Moreover, the samples show endothermic peaks at $110-140{ }^{\circ} \mathrm{C}$, which may be attributed to $\alpha$-helical transition [28,29].

Table 1. Properties of peptidic triblocks.

\begin{tabular}{ccccc}
\hline Samples & Peptide Content (\%) & $\beta$-Sheet Content $(\%)$ & $T_{\mathrm{g}}\left({ }^{\circ} \mathrm{C}\right)$ & $\boldsymbol{T}_{\mathrm{m}}\left({ }^{\circ} \mathrm{C}\right)$ \\
\hline P3 & 39.6 & 83.0 & 31 & 118 \\
P7 & 60.5 & 48.4 & 35 & 135 \\
\hline
\end{tabular}

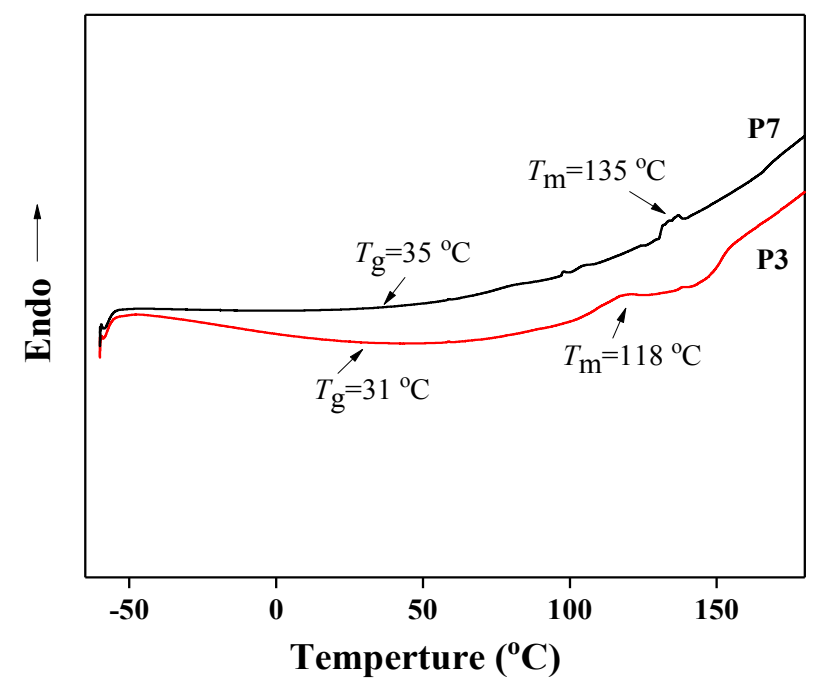

Figure 3. Differential scanning calorimetry (DSC) curves of P3 and P7.

\subsection{Preparation and Properties of Peptide-Polyurethane/Ureas}

As shown in Scheme 2, the peptide-polyurethane/ureas (P3-PU and P7-PU) were prepared using IPDI as the hard segment, PTMEG2000 as the soft phase and PBLG as the peptide segment. The peptide contents in P3-PU and P7-PU were $~ 14 \%$ and $25 \%$, respectively. FTIR spectra were used to characterize these two samples, as shown in Figure 4. The strong absorptions at $\sim 1730 \mathrm{~cm}^{-1}$ are assigned to the 
stretching vibration of $\mathrm{C}=\mathrm{O}$ in urethane units and benzyl ester groups, while the peaks at $\sim 1650 \mathrm{~cm}^{-1}$ are attituded to the $\mathrm{C}=\mathrm{O}$ stretching vibration in urea units and amide I regions ( $\alpha$-helix). Compared with those of peptidic triblocks, these two peaks become strong, indicating the formation of urethane and urea linkages. Moreover, the strong bands at $\sim 3280 \mathrm{~cm}^{-1}$ and $1625 \mathrm{~cm}^{-1}$ are corresponding to the $\mathrm{N}-\mathrm{H}$ stretching vibration and antiparallel $\beta$-sheet in peptidic triblocks. These results also demonstrate the obtained peptide-polyurethane/ureas have mixed $\alpha$-helix and $\beta$-sheet structure.

Morphological studies by WAXD and AFM could further elucidate the structural characteristics of the obtained peptide-polyurethane/ureas. Figure 5 exhibits WAXD profiles of P3-PU and P7-PU. The diffraction peaks at $2 \theta=17.8^{\circ}(\mathbf{P 3}-\mathbf{P U})$ and $19.0^{\circ}(\mathbf{P 7}-\mathbf{P U})$ representing the diffraction of $(020)$ plane could be ascribed to the $\beta$-sheet crystalline structure [30]. This indicates that the peptides still exhibit $\beta$-sheet conformation even upon incorporation into polyurethane/ureas. Moreover, the diffraction peak intensity of P3-PU is higher than that of P7-PU, which is due to high $\beta$-sheet content in P3-PU. Figure 6 shows the phase morphology of P7-PU. Nanofibrous structure was observed in the P7-PU film. This was consistent with previously reported peptide-polymer conjugates where hydrogen bonding motifs played a dominant role in the development of microstructures [20].

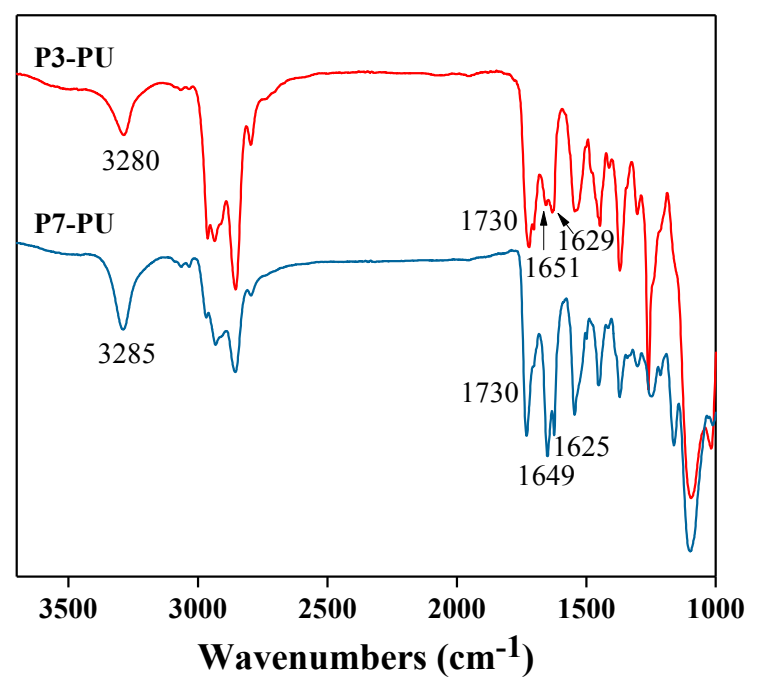

Figure 4. FTIR spectra of P3-PU and P7-PU.

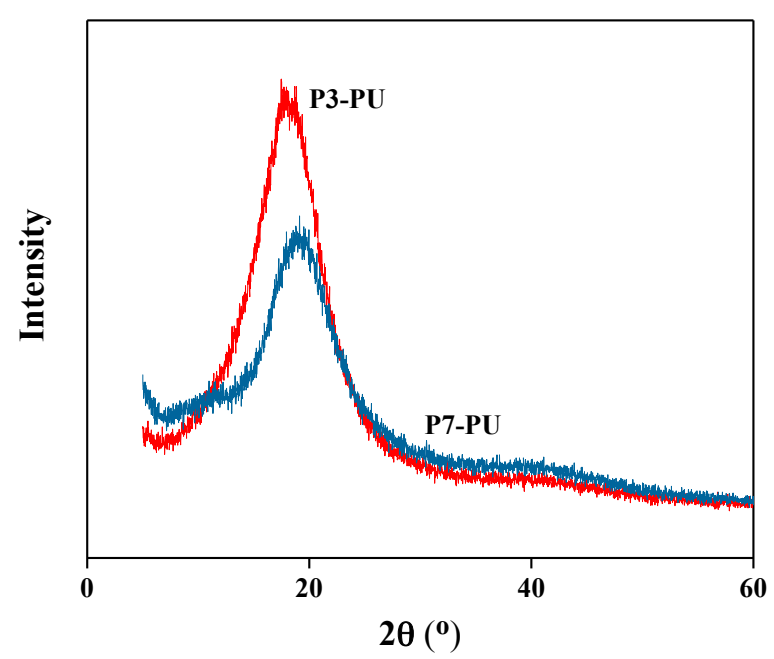

Figure 5. Wide angle X-ray diffraction (WAXD) profiles of P3-PU and P7-PU. 


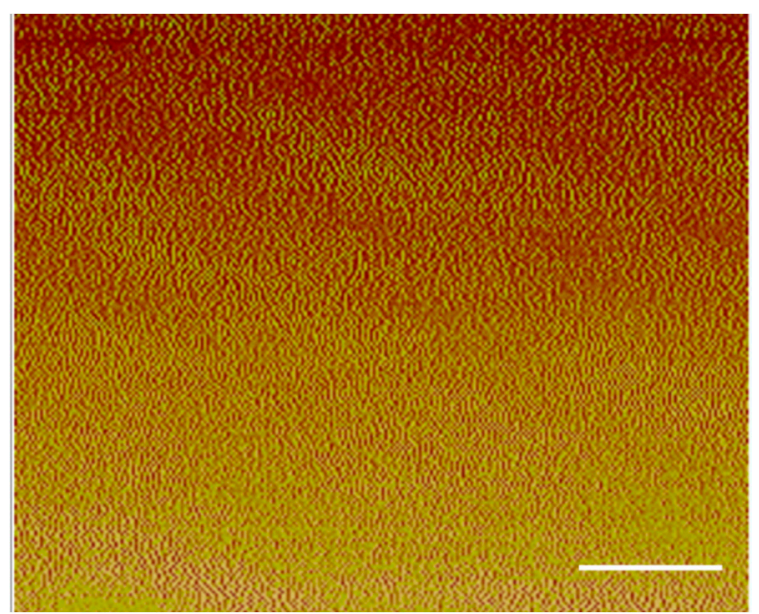

Figure 6. Atomic force microscopy (AFM) phase image of P7-PU. The scale bar is $40 \mathrm{~nm}$.

In general, thermoplastic polyurethane/ureas display multiple thermal transitions which correspond to the individual chemical components of the microphase-separated polymer [15]. The thermal transitions of P3-PU and P7-PU were investigated by DSC. Figure 7 displays the DSC curves of P3-PU and P7-PU during heating process. Two endothermic peaks were clearly observed, corresponding to PTMEG units $\left(T_{\mathrm{m} 1}\right)$ and $\alpha$-helical transition $\left(T_{\mathrm{m} 2}\right)$ in PBLG- $b$-PPG- $b$-PBLG, which were summarized in Table 2. The $\alpha$-helical transition temperature $T_{\mathrm{m} 2}$ of P3-PU and P7-PU decreased compared with the pure components, possibly due to the increased mobility induced by the soft PTMEG. Figure 8 shows the TGA results of P3-PU and P7-PU. The onset decomposition temperature ( $5 \%$ weight-loss temperature) of these two samples was above $280{ }^{\circ} \mathrm{C}$, indicating their good thermal stability.

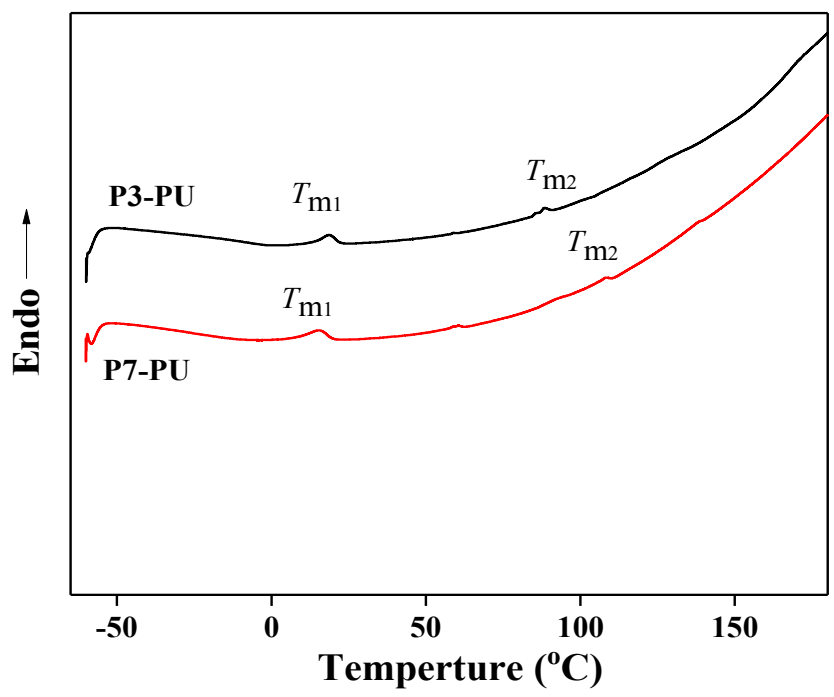

Figure 7. DSC curves of P3-PU and P7-PU.

Table 2. Thermal and mechanical properties of peptide-polyurethane/ureas.

\begin{tabular}{cccccc}
\hline Samples & $\boldsymbol{T}_{\mathrm{m} 1}\left({ }^{\circ} \mathbf{C}\right)$ & $\boldsymbol{T}_{\mathrm{m} 2}\left({ }^{\circ} \mathbf{C}\right)$ & Tensile Strength (MPa) & Elongation (\%) & Young's Modulus (KPa) \\
\hline P3-PU & 18.6 & 88.3 & 0.25 & 2210 & 226 \\
P7-PU & 15.5 & 108.6 & 4.69 & 1650 & 513 \\
\hline
\end{tabular}




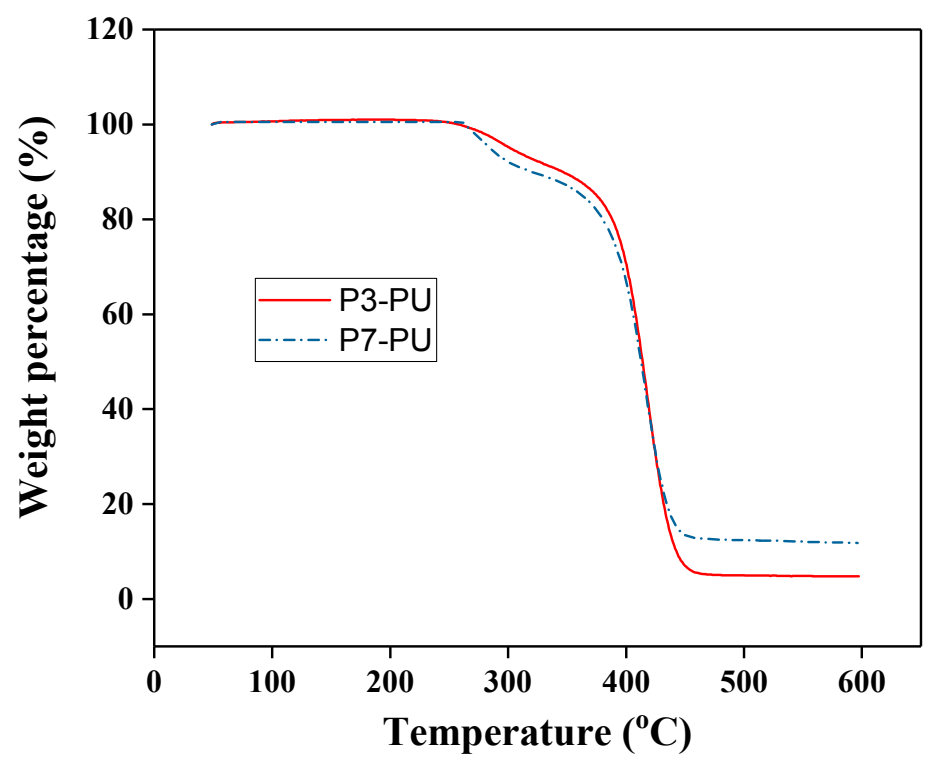

Figure 8. Thermogravimetric analysis (TGA) curves of P3-PU and P7-PU.

Mechanical properties of P3-PU and P7-PU were examined by tensile test. Figure 9 shows the stress-strain curves, and their tensile strength, elongation and Young's modulus are listed in Table 2. They display medium tensile strength $(0.25-4.6 \mathrm{MPa})$, high stretchability $(>1600 \%)$, human-tissue-compatible Young's modulus $(226-513 \mathrm{KPa})$, which would have various potential applications such as wearable and implantable electronics, and biomedical devices. Compared to P3-PU, P7-PU exhibits higher tensile strength and Young's modulus because of its higher peptide content. It has been reported by that tensile strength and modulus of peptide-polyureas was increased with increased peptide weight fraction, most likely due to the "pseudo" hard segment character of the PBLG blocks $[19,20]$. Figure 10 shows cyclic tensile curves of the two samples at a strain $\varepsilon_{\mathrm{m}}=500 \%$, and the corresponding values of the shape recovery ratio $\left(R_{\mathrm{r}}\right)$ are summarized in Figure 11. It can be found that all the values of $R_{\mathrm{r}}$ are above $60 \%$ during successive cycles at high strain, which may be due to the existing $\beta$-sheet structures as netpoints [17]. Especially, the $R_{\mathrm{r}}$ of P7-PU is above $85 \%$ during the first cycle and $>95 \%$ after that, indicating good stability in shape.

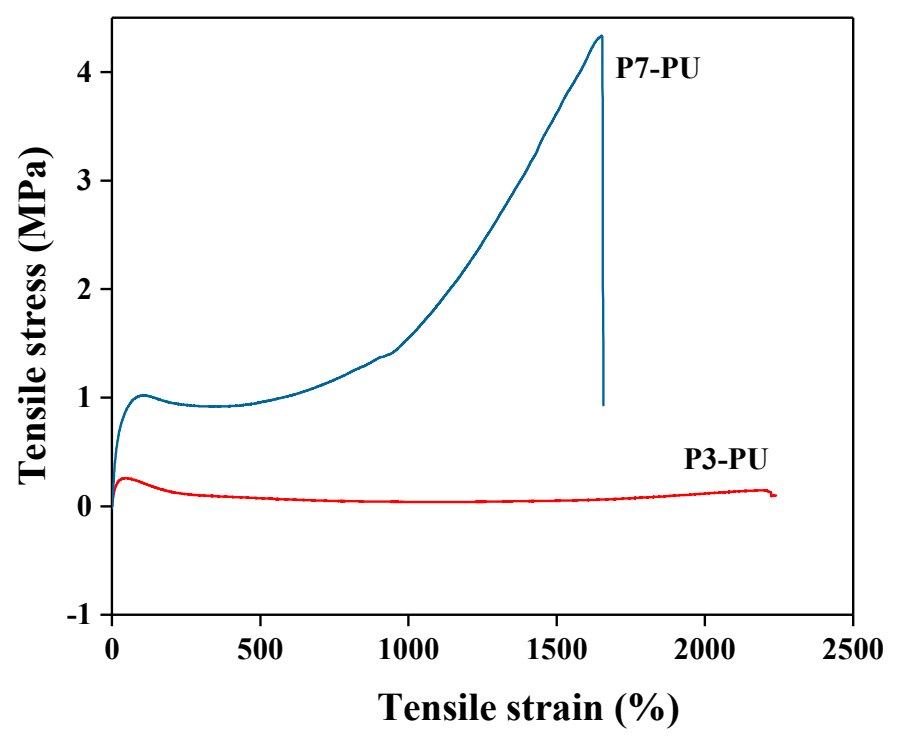

Figure 9. Stress-strain curves of P3-PU and P7-PU. 

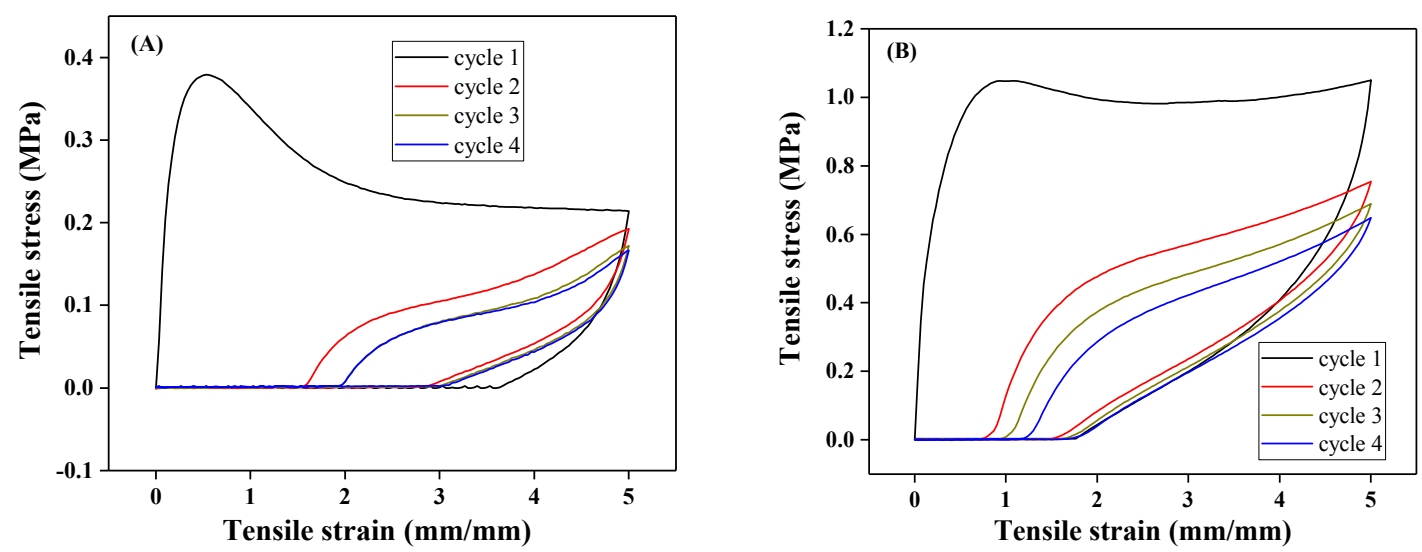

Figure 10. Cyclic tensile curves of P3-PU (A) and P7-PU (B) at a strain $\varepsilon_{\mathrm{m}}=500 \%$.

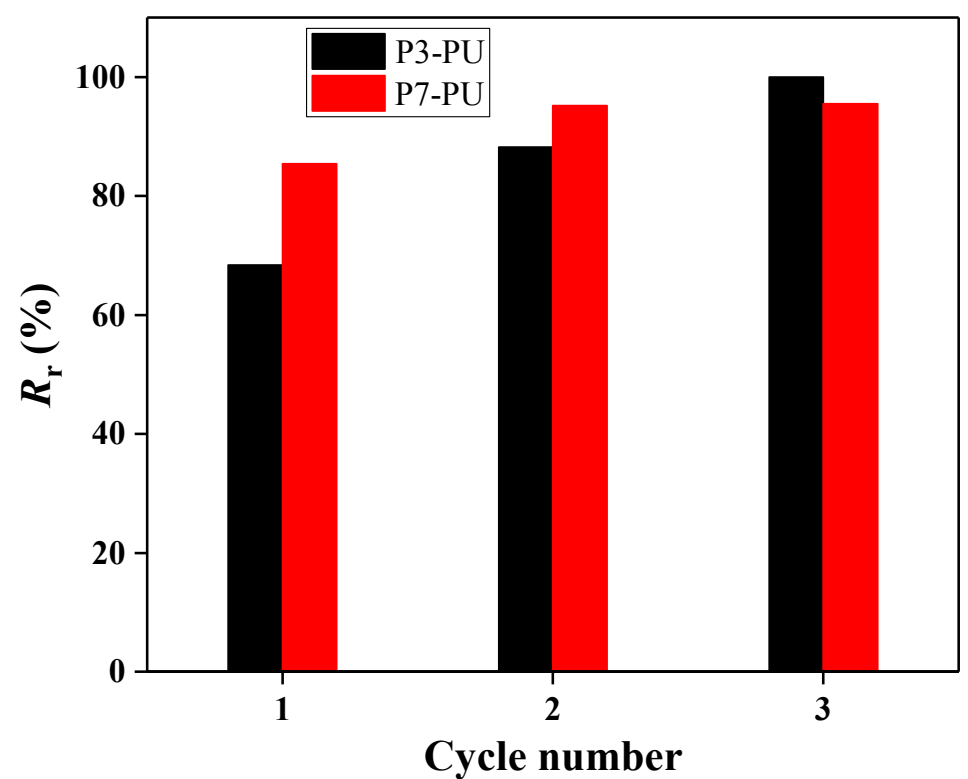

Figure 11. The strain recovery ratio $\left(R_{\mathrm{r}}\right)$ during cyclic stretch.

\section{Conclusions}

PBLG- $b$-PPG- $b$-PBLG with short peptide segment length ( $<10$ residues) was synthesized by amine-initiated ring opening polymerization of BLG-NCA. The obtained peptidic triblocks show mixed $\alpha$-helix and $\beta$-sheet conformation, and the percent of $\beta$-sheet structure was above $48 \%$. A new class of peptide-polyurethane/ureas were synthesized containing a peptidic triblock soft segment, which also exhibit both $\alpha$-helix and $\beta$-sheet structure. The obtained PUUs display medium tensile strength $(0.25-4.6 \mathrm{MPa})$, high stretchability $(>1600 \%)$, human-tissue-compatible Young's modulus (226-513 KPa). Furthermore, the shape recovery ratio could reach above $85 \%$ during successive cycles at high strain (500\%). We believe this work will provide new insight for developing polypeptide materials, which would have various potential applications such as wearable and implantable electronics, and biomedical devices.

Author Contributions: L.G. and J.H. conceived and designed the experiments; Y.J. and L.G. performed the experiments; L.G. and Y.J. analyzed the data; L.G. wrote the paper. 
Acknowledgments: This work was financially supported by the National Natural Science Foundation of China (51673162), Research Grants Council, University Grants Committee (PolyU 5158/13E), Science and Technology Planning Project of Guangdong Province, China (Project Number: 2016A050503013), and Hong Kong Scholars Program (XJ2016052).

Conflicts of Interest: The authors declare no conflict of interest.

\section{References}

1. Ritchie, R.O. The conflicts between strength and toughness. Nat. Mater. 2011, 10, 817-822. [CrossRef] [PubMed]

2. Meyers, M.A.; McKittrick, J.; Chen, P.-Y. Structural Biological Materials: Critical Mechanics-Materials Connections. Science 2013, 339, 773-779. [CrossRef] [PubMed]

3. Johnson, J.C.; Korley, L.T.J. Enhanced mechanical pathways through nature's building blocks: Amino acids. Soft Matter 2012, 8, 11431-11442. [CrossRef]

4. Olsen, B.D. Engineering materials from proteins. AIChE J. 2013, 59, 3558-3568. [CrossRef]

5. Anton, A.M.; Heidebrecht, A.; Mahmood, N.; Beiner, M.; Scheibel, T.; Kremer, F. Foundation of the Outstanding Toughness in Biomimetic and Natural Spider Silk. Biomacromolecules 2017, 18, 3954-3962. [CrossRef] [PubMed]

6. Lawrence, B.A.; Vierra, C.A.; Moore, A.M.F. Molecular and Mechanical Properties of Major Ampullate Silk of the Black Widow Spider, Latrodectus hesperus. Biomacromolecules 2004, 5, 689-695. [CrossRef] [PubMed]

7. Scavuzzo, J.J.; Yan, X.; Zhao, Y.; Scherger, J.D.; Chen, J.; Zhang, S.; Liu, H.; Gao, M.; Li, T.; Zhao, X.; et al. Supramolecular Elastomers. Particulate $\beta$-Sheet Nanocrystal-Reinforced Synthetic Elastic Networks. Macromolecules 2016, 49, 2688-2697. [CrossRef]

8. Mithieux, S.M.; Rasko, J.E.J.; Weiss, A.S. Synthetic elastin hydrogels derived from massive elastic assemblies of self-organized human protein monomers. Biomaterials 2004, 25, 4921-4927. [CrossRef] [PubMed]

9. Bonduelle, C. Secondary structures of synthetic polypeptide polymers. Polym. Chem. 2018, 9, 1517-1529. [CrossRef]

10. Tsuchiya, K.; Numata, K. Chemical Synthesis of Multiblock Copolypeptides Inspired by Spider Dragline Silk Proteins. ACS Macro Lett. 2017, 6, 103-106. [CrossRef]

11. Winningham, M.J.; Sogah, D.Y. A Modular Approach to Polymer Architecture Control via Catenation of Prefabricated Biomolecular Segments: Polymers Containing Parallel $\beta$-Sheets Templated by a Phenoxathiin-Based Reverse Turn Mimic. Macromolecules 1997, 30, 862-876. [CrossRef]

12. Rathore, O.; Sogah, D.Y. Self-Assembly of $\beta$-Sheets into Nanostructures by Poly(alanine) Segments Incorporated in Multiblock Copolymers Inspired by Spider Silk. J. Am. Chem. Soc. 2001, 123, 5231-5239. [CrossRef] [PubMed]

13. Rathore, O.; Sogah, D.Y. Nanostructure Formation through $\beta$-Sheet Self-Assembly in Silk-Based Materials. Macromolecules 2001, 34, 1477-1486. [CrossRef]

14. Martino, M.; Perri, T.; Tamburro, A.M. Elastin-Based Biopolymers: Chemical Synthesis and Structural Characterization of Linear and Cross-Linked Poly(OrnGlyGlyOrnGly). Biomacromolecules 2002, 3, $297-304$. [CrossRef] [PubMed]

15. Johnson, J.C.; Wanasekara, N.D.; Korley, L.T.J. Utilizing Peptidic Ordering in the Design of Hierarchical Polyurethane/Ureas. Biomacromolecules 2012, 13, 1279-1286. [CrossRef] [PubMed]

16. Clarke, D.E.; Pashuck, E.T.; Bertazzo, S.; Weaver, J.V.M.; Stevens, M.M. Self-Healing, Self-Assembled $\beta$-Sheet Peptide-Poly $(\gamma$-glutamic acid) Hybrid Hydrogels. J. Am. Chem. Soc. 2017, 139, 7250-7255. [CrossRef] [PubMed]

17. Huang, H.; Hu, J.; Zhu, Y. Shape-memory biopolymers based on beta-sheet structures of polyalanine segments inspired by spider silks. Macromol. Biosci. 2013, 13, 161-166. [CrossRef] [PubMed]

18. Tanaka, S.; Ogura, A.; Kaneko, T.; Murata, Y.; Akashi, M. Precise Synthesis of ABA Triblock Copolymers Comprised of Poly(ethylene oxide) and Poly( $\beta$-benzyl-L-aspartate): A Hierarchical Structure Inducing Excellent Elasticity. Macromolecules 2004, 37, 1370-1377. [CrossRef]

19. Johnson, J.C.; Wanasekara, N.D.; Korley, L.T.J. Influence of secondary structure and hydrogen-bonding arrangement on the mechanical properties of peptidic-polyurea hybrids. J. Mater. Chem. B 2014, 2, $2554-2561$. [CrossRef] 
20. Matolyak, L.; Keum, J.; Korley, L.T.J. Molecular Design: Network Architecture and Its Impact on the Organization and Mechanics of Peptide-Polyurea Hybrids. Biomacromolecules 2016, 17, 3931-3939. [CrossRef] [PubMed]

21. Gu, L.; Jiang, Y.; Hu, J. Synthesis and Properties of Shape Memory Poly( $\gamma$-Benzyl-L-Glutamate)- $b$ Poly(Propylene Glycol)-b-Poly( $\gamma$-Benzyl-L-Glutamate). Appl. Sci. 2017, 7, 1258. [CrossRef]

22. Guo, A.-R.; Yang, W.-X.; Yang, F.; Yu, R.; Wu, Y.-X. Well-Defined Poly( $\gamma$-benzyl-L-glutamate)g-Polytetrahydrofuran: Synthesis, Characterization, and Properties. Macromolecules 2014, 47, 5450-5461. [CrossRef]

23. Gu, L.; Wu, Q.-Y. Recyclable bio-based crosslinked polyurethanes with self-healing ability. J. Appl. Polym. Sci. 2018, 135, 46272. [CrossRef]

24. Gu, L.; Cui, B.; Wu, Q.-Y.; Yu, H. Bio-based polyurethanes with shape memory behavior at body temperature: Effect of different chain extenders. RSC Adv. 2016, 6, 17888-17895. [CrossRef]

25. Cui, B.; Wu, Q.-Y.; Gu, L.; Shen, L.; Yu, H.-B. High performance bio-based polyurethane elastomers: Effect of different soft and hard segments. Chin. J. Polym. Sci. 2016, 34, 901-909. [CrossRef]

26. Lee, N.H.; Frank, C.W. Surface-Initiated Vapor Polymerization of Various $\alpha$-Amino Acids. Langmuir 2003, 19, 1295-1303. [CrossRef]

27. Kotharangannagari, V.K.; Sánchez-Ferrer, A.; Ruokolainen, J.; Mezzenga, R. Thermoreversible Gel-Sol Behavior of Rod-Coil-Rod Peptide-Based Triblock Copolymers. Macromolecules 2012, 45, 1982-1990. [CrossRef]

28. Sánchez-Ferrer, A.; Mezzenga, R. Secondary Structure-Induced Micro- and Macrophase Separation in Rod-Coil Polypeptide Diblock, Triblock, and Star-Block Copolymers. Macromolecules 2010, 43, 1093-1100. [CrossRef]

29. Wei, M.-J.; Guo, A.-R.; Wu, Y.-X. Microstructure and Micromorphology of Poly ( $\gamma$-benzyl-L-glutamate)-g(Polytetrahydrofuran-b-Polyisobutylene) Copolymer. Acta Polym. Sin. 2017, 3, 506-515.

30. Wang, Q.; Yanzhang, R.; Wu, Y.; Zhu, H.; Zhang, J.; Du, M.; Zhang, M.; Wang, L.; Zhang, X.; Liang, X. Silk-derived graphene-like carbon with high electrocatalytic activity for oxygen reduction reaction. RSC Adv. 2016, 6, 34219-34224. [CrossRef] 